\title{
Active Control of Surge Compressor System
}

\section{Abo-khsheem KA*}

Electric \& Electronics Department, Bright Star University, AL-Brega, Libya

\begin{abstract}
Surge is an unstable operating mode of a compression system that occurs at mass flows below the so-called surge line. The instability is characterized by large limit cycle oscillations in compressor flow and pressure rise that reduce compressor performance. The paper described the dynamic behaviour of centrifugal compressors. Then the compression system model is used to design an active surge control system. The developed surge control system was implemented on MATLAB-SIMULINK program with data of Solar Compressor in SIRT Oil Co. and presented in a simple form.
\end{abstract}

Keywords: Centrifugal compressor; Surge phenomenon; Active control

\section{Introduction}

Today and along our country tens of plant are working and producing different types of oil and gas productions [1]. In any of these plants there is much equipment. Centrifugal compressors are the most widely used. Operation of these compressors is clearly difficult and many problems can be occurred due to operation of these power equipment. The main difficult of understanding the problems is to know the surge problem in centrifugal and axial flow compressors [2]. Today it is clear that the challenge to face with this problem is duty of our engineers and operators. It requires a lot of effort to understand and overcome these difficulties.

The most common surge protection mechanism is flow recycling. This method causes a considerable waste of energy, specifically, when the valve has to respond to sudden changes in flow which results in a great deal of overshooting in the recycled flow [3]. Active control is still an active field of research with many promises to improve the performance and efficiency of compressors [4]. The paper explains the surge phenomenon and described the dynamic behaviour of centrifugal compressors. Then the compression system model is used to design an active surge control system. Finally, the developed surge control system was implemented with real data of Solar Compressor in SIRT oil Co. on MATLAB-SIMULINK program and presented in forms to show the different side of the problem.

\section{Instability in Centrifugal Compressors}

The stable operating range of compressors is limited at low and high mass flow rates by surge, rotating stall (choke) or a combination of both. Rotating stall and surge have been a problem for compressors as long as these machines have existed [5]. No matter which one of these flow instabilities occur, it has big effects on the system and must be avoided. Figure 1 shows these limits on the compressors performance map [2,6]. Pressure and mass flow oscillations associated with compressor surge cause the blades to heat up quickly and the exhaust temperature of the compressor to increase. Furthermore, these fluctuations result in unacceptable blade loads that can cause severe blade vibration and fatigue. Figure 2 shows the damage to an Elliott 90P Centrifugal Compressor after the compressor underwent surge [7].

\section{Surge Protection}

Surge protection mechanisms divide into two major groups: surge detection and avoidance and active surge control. In surge avoidance schemes, when the onset of surge is detected a surge avoidance system such as a bleed or recycle valve will be activated to move the operating point of the system to a point away from the surge line as shown in Figure 3. In the active surge control system, the compression system parameters are constantly monitored by various sensors, a controller provides the required signal to actuators that will influence system parameters and stabilize the operating point. The operating point of the compressor is set by mass flow rate, pressure ratio and rotational speed.

Therefore, a surge avoidance method should influence at least one of these parameters. Other methods try to modify the torque on the compressor by increasing or decreasing the rotational speed. This can be done by changing the motor speed or fuel consumption. The other way to control surge would be to target changing the pressure ratio by manipulating valves in the flow. Mass flow rate, pressure ratio and rotational speed are connected through the compressor characteristic map. Therefore, modifying one influences the others [8].

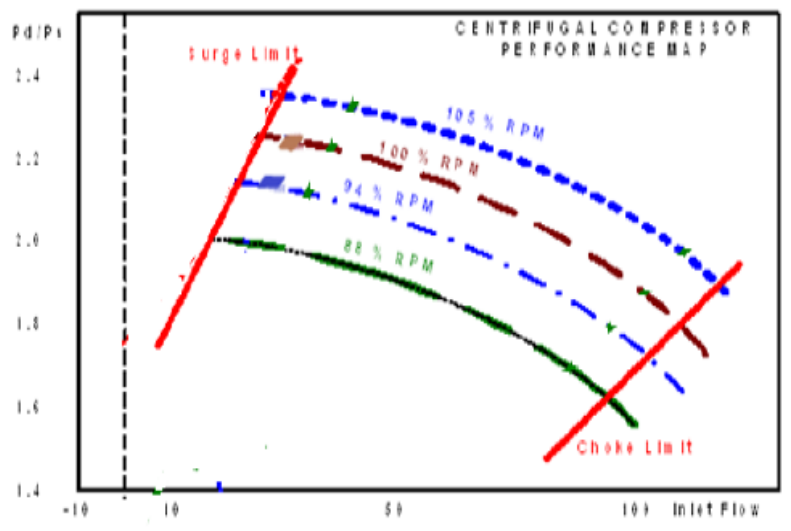

Figure 1: Limits on the compressors performance map.

*Corresponding author: Abo-khsheem KA, Assistant Professor, Electric \& Electronics Department, Bright Star University, AL-Brega, Libya, Tel: 0218914565552; E-mail: Khalfhusain@gmail.com

Received July 07, 2018; Accepted July 30, 2018; Published August 04, 2018

Citation: Abo-khsheem KA (2018) Active Control of Surge Compressor System. J Electr Electron Syst 7: 267. doi: 10.4172/2332-0796.1000267

Copyright: (c) 2018 Abo-khsheem KA. This is an open-access article distributed under the terms of the Creative Commons Attribution License, which permits unrestricted use, distribution, and reproduction in any medium, provided the original author and source are credited. 

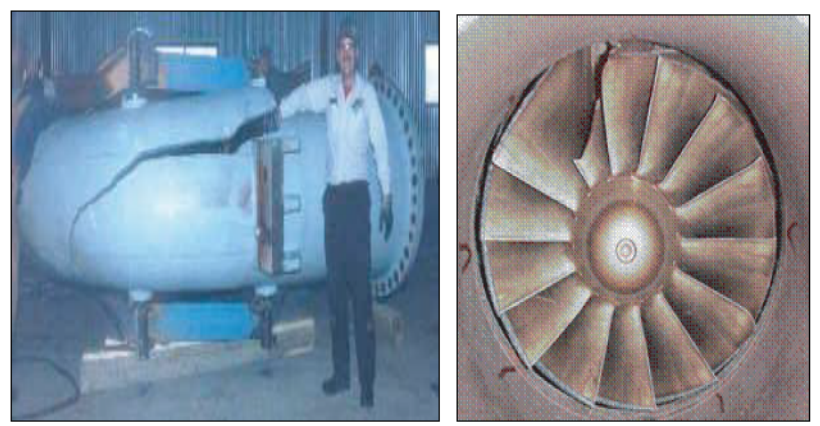

Figure 2: Damage to centrifugal compressor

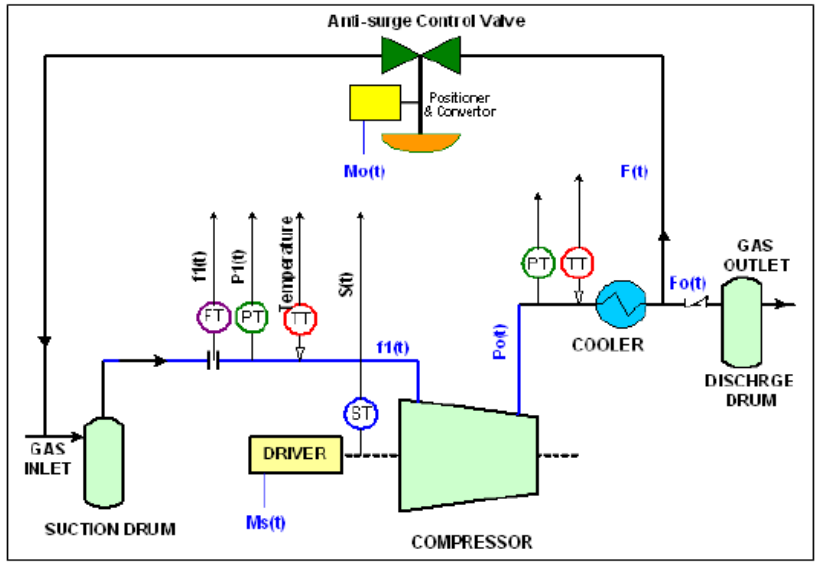

Figure 3: Centrifugal compressor with recycling valve system.

The main difference between these methods is in the instruments used for detecting surge and the actuator's response time in preventing the machine from going into deep surge after surge has been detected.

\section{Modelling of Centrifugal Compressors}

In this chapter we develop the mathematic model, transfer function and block diagram of compressor system.

1. The inlet flow is a function of compressor speed and given experimentally by an equation for each compressor or defined from compressors performance graphs. It takes the form [7]:

$$
f_{1}(\mathrm{t})=A_{1} * m_{\mathrm{s}}(t)+\mathrm{b}
$$

Where $\mathrm{A} 1$ and $\mathrm{b}$ are constants

2. The flow through anti-surge valve can be written and calculated on the base of valve flow formula [9]:

$$
f_{2}(t)=A_{2} * m_{\mathrm{o}}(t) \sqrt{P_{\mathrm{o}}(t)\left[P_{\mathrm{o}}(t)-P_{i}(t)\right.}
$$

Where $\mathrm{A} 2$ is a constant

3. An un-steady state model can be written around the steady state condition of the control volume:

$\mathrm{V}$ : Volume of discharge piping $($ Plenum $)=\mathrm{ft}^{3}$,

$f_{1}$ : Steady state inlet flow,

$P_{1}:$ Inlet pressure $=$ psia,

$p_{\mathrm{o}}:$ Outlet pressure $=\mathrm{psia}$, $m_{\mathrm{s}}$ : Steady state signal to speed control $=\%$

$m_{\mathrm{o}}$ : Steady state signal to anti-surge control valve $=\%$

$p_{s}:$ Steady state pressure in the piping system after the check valve.

An un-steady state model of material balance around the control volume $\mathrm{V}$ can be written [9]:

Rate of gas moles into control volume - Rate of gas moles out of control volume $=$ Rate of gas accumulated moles in the volume .

Or

$$
\rho\left[f_{1}(\mathrm{t})\right]-\rho\left[f_{o}(t)+f_{2}(t)\right]=d n(t) / d(t)
$$

Where $\mathrm{n}(\mathrm{t})$ - gas mole in $\mathrm{V}$ and $\rho$ - mole density of gas at standard conditions: $\mathrm{T}=60^{\circ} \mathrm{F}$ and $\mathrm{P}=1$ at.

4. We consider, that gas is ideal and the gas equation describes the mole in the volume $\mathrm{V}$ space at pressure $\mathrm{Po}(\mathrm{t})$, or

$$
\begin{aligned}
& P_{O}(\mathrm{t}) * V=n(t) R T \\
& n(t)=(V / R T)
\end{aligned}
$$

By substituting (4) in (3) we can write:

$$
\rho\left[f_{1}(\mathrm{t})\right]-\rho\left[f_{o}(t)+f_{2}(t)\right]=(V / R T) * D p_{O}(t) / d t
$$

The outlet flow $f_{0}(\mathrm{t})$ can be measured and calculated by an orifice plate formula [9]

$$
f_{\mathrm{o} P}(t)=\left(C / \sqrt{1-\beta^{4}}\right) * \varepsilon \pi / 4 * d^{2} \sqrt{2 \rho P \Delta P_{\mathrm{o}}}(t)
$$

Where $\Delta \mathrm{P}(\mathrm{t})=\mathrm{P}_{\mathrm{o}}(\mathrm{t})-\mathrm{P}_{\mathrm{s}}$ is the differential pressure across the orifice. Some of the equations are nonlinear. We use Tailor formula for equation (2):

$$
f_{2}(t)=f_{2}+\partial f_{2} /\left.\partial m_{\mathrm{o}}\right|_{\mathrm{ss}}\left[m_{\mathrm{o}}(\mathrm{t})-m_{\mathrm{o}}\right]+\partial f_{2} /\left.\partial P_{\mathrm{o}}\right|_{\mathrm{ss}}\left[P_{\mathrm{o}}(t)-P_{\mathrm{o}}\right]+\partial f_{2} / \partial
$$
$P_{1}\left[P_{1}(t)-P_{1}\right]$

The constants C1, C2, C3 can be calculated for a specific data. Nonlinear equation (6) of outlet flow through orifice plate can be linearized in the same manner

$$
\begin{aligned}
& C_{1}=\partial f_{2} /\left.\partial m_{\mathrm{o}}\right|_{\mathrm{ss}}=A_{2} *\left[P_{\mathrm{o}}\left(P_{\mathrm{o}}-P_{1}\right)\right]^{2} \\
& \left.C_{2}=\partial f_{2} /\left.\partial P_{\mathrm{o}}\right|_{\mathrm{ss}}=A_{2} * m_{\mathrm{o}} *(1 / 2)\left(2 P_{\mathrm{o}}-P_{1}\right)\right] /\left[P_{\mathrm{o}}\left(P_{\mathrm{o}}-P_{1}\right)\right]^{2} \\
& \left.C_{3}=\partial f_{2} /\left.\partial P_{1}\right|_{\mathrm{ss}}=A_{2} * m_{\mathrm{o}} *(1 / 2)\left(2 P_{\mathrm{o}}-P_{1}\right)\right] /\left[P_{\mathrm{o}}\left(P_{\mathrm{o}}-P_{1}\right)\right]^{2} \\
& \left.f_{0}(\mathrm{t})=f_{o}+\partial f_{\mathrm{o}} /\left.\partial P_{\mathrm{o}}\right|_{\mathrm{ss}} P_{\mathrm{o}}(\mathrm{t})-P_{\mathrm{o}}\right] \\
& \left.f_{0}(\mathrm{t})=f_{o}+\partial f_{\mathrm{o}} /\left.\partial P_{\mathrm{o}}\right|_{\mathrm{ss}} P_{\mathrm{o}}(\mathrm{t})-P_{\mathrm{o}}\right] \\
& C_{4}=\mathrm{A}_{3} *(1 / 2)[2 \rho] / 2 \rho\left[P_{\mathrm{o}}(\mathrm{t})-P_{S}\right]
\end{aligned}
$$

Application of mathematical model is written by a set of equations after linearization we receive the actual mathematic model of antisurge control system:

$$
\begin{aligned}
& f_{1}(\mathrm{t})=A_{1} * m_{\mathrm{s}}(t)+\mathrm{b} \\
& f_{2}(t)=f_{2}+C_{1} *\left[m_{\mathrm{o}}(\mathrm{t})-m_{\mathrm{o}}\right]+C_{1} *\left[P_{\mathrm{o}}(\mathrm{t})-P_{\mathrm{o}}\right]+C_{3} *\left[P_{1}(\mathrm{t})-P_{1}\right] \\
& \rho\left[f_{1}(\mathrm{t})\right]-\rho\left[f_{0}(t)+f_{2}(t)\right]=d n(t) / d(t)
\end{aligned}
$$

\section{Transfer Function and Block Diagram of Compressor System}

1. Definition of deviation variables: Writing the steady-state equations, subtracting them from their respecting counterparts, and defining the required deviation variables. 
The steady-state mole balance around the compressor:

$\rho\left[f_{1}(\mathrm{t})\right]-\rho\left[f_{o}(t)+f_{2}(t)\right]=0$

Subtracting this equation from (2) gives

$\rho\left[f_{1}(\mathrm{t})-f_{1}\right]-\rho\left[f_{o}(t)-f_{o}+f_{2}(t)-f_{2}\right]=(V / R T) * d\left[P_{\mathrm{o}}(\mathrm{t})-P_{\mathrm{o}}\right] / d t$

Where $\mathrm{P}_{\mathrm{o}}$ steady state pressure

Defining the following deviation variables:

$F_{1}(\mathrm{t})=f_{1}(\mathrm{t})-f_{1}, F_{\mathrm{o}}(\mathrm{t})=f_{\mathrm{o}}(\mathrm{t})-f_{\mathrm{o}}, F_{2}(\mathrm{t})=f_{2}(\mathrm{t})-f_{2}$ and $P_{\mathrm{o}}(\mathrm{t})=P_{\mathrm{o}}(\mathrm{t})-P_{\mathrm{o}}$

Substituting these variables into equation (7) yield

$\rho\left[F_{1}(t)\right]-\rho\left[F_{\mathrm{o}}(t)+F_{2}(t)\right]=(V / R T) * d P_{\mathrm{o}}(\mathrm{t}) / d t$

Writing the steady-state equation for the inlet flow in the same manner

yield:

$F_{1}(\mathrm{t})=A_{1} * M_{s}(t)$

Where $M_{s}(\mathrm{t})=m_{\mathrm{s}}(\mathrm{t})+\mathrm{b}$

From (2) we can find

$F_{2}(\mathrm{t})=C_{1} * M_{\mathrm{o}}(\mathrm{t})+C_{2} * P_{\mathrm{o}}(\mathrm{t})+C_{3} * P_{1}(t)$

where

$M_{\mathrm{o}}(\mathrm{t})=m_{\mathrm{o}}(\mathrm{t})-m_{\mathrm{o}} ; P_{1}(\mathrm{t})=\mathrm{p}_{1}(\mathrm{t})-\mathrm{p}_{1}$ and $P_{\mathrm{o}}(\mathrm{t})=p_{\mathrm{o}}(\mathrm{t})-p_{\mathrm{o}}$

From (8) we have

$\rho\left[F_{1}(\mathrm{t})\right]-\rho\left[F_{o}(t)+F_{2}(t)\right]=(V / R T) * d P_{\mathrm{o}}(\mathrm{t}) / d t$

From (6) we have

$F_{1}(\mathrm{t})=A_{1} * M_{s}(t)$

We have four equations in deviation forms (6), (9), (10) and (11) with

four unknowns $F_{1}(t), F_{o}(t), F_{2}(t)$ and $P_{o}(t)$.

Substitute from (6), (9) and (11) in (10) we receive:

$A_{1} M_{s}(t)-C_{4} * P_{\mathrm{o}}(t)-C_{1} * M_{\mathrm{o}}(\mathrm{t})-C_{2} * P_{\mathrm{o}}(\mathrm{t})-C_{3} * P_{1}(\mathrm{t})=(V / R T \rho)$ $* d P_{\mathrm{o}}(\mathrm{t}) / d(t)$

$A_{1} M_{s}(t)-C * M_{\mathrm{o}}(\mathrm{t})-C_{3} * P_{1}(\mathrm{t})=\left[C_{2}+\mathrm{C}_{4}\right] * P_{\mathrm{o}}(\mathrm{t})+(V / R T \rho) *$ $d P_{\mathrm{o}}(\mathrm{t}) / d(t)$

Taking the LAPLAC transform and rearranging, yield

$A_{1} M_{s}(S)-C_{1} * M_{\mathrm{o}}(S)-C_{3} * P_{1}(S)=\left\{\left[C_{2}+\mathrm{C}_{4}\right]+(V / R T \rho) * S\right\} P_{\mathrm{o}}(S)$

$$
P_{o}(S)=\frac{K_{1}}{\tau S+1} M s(S)-\frac{K_{2}}{\tau S+1} \operatorname{Mo}(S)+\frac{7.4}{\tau S+1} P_{1}(S)
$$

Where

$$
\mathrm{K}_{1}=\frac{\mathrm{A}_{1}}{\mathrm{C}_{4}+\mathrm{C}_{2}}, \mathrm{~K}_{2}=\frac{\mathrm{C}_{1}}{\mathrm{C}_{2}+\mathrm{C}_{4}}, \mathrm{~K}_{3}=\frac{\mathrm{C}_{3}}{\mathrm{C}_{2}+\mathrm{C}_{4}}, \tau=\frac{\mathrm{V}}{\left(\mathrm{C}_{4}+\mathrm{C}_{2}\right)^{*} R T \rho}
$$

All of the transfer functions are of first order. Because the steadystate values and other process information are known, all gains and the time constant can be evaluated [10].

These constant values are applied to Solar Compressor in SIRT oil Co. with the data shown in Table 1:
The calculations of these coefficients give:

$\mathrm{C}_{1}=2633333, \mathrm{C}_{2}=6000 ; \mathrm{C}_{3}=1575 ; \mathrm{C}_{4}=15150$

$A_{1}=351110 ; A_{2}=6100$ and $A_{3}=22585$.

After substituting in the above transfer function we received:

$\mathrm{K}_{1}=16.6 ; \mathrm{K}_{2}=124 ; \mathrm{K}_{3}=7.4$ and $=27.3 \mathrm{~s}$

The transfer function of the system

$\operatorname{Po}(S)=\frac{16.6}{27.3 S+1} \operatorname{Ms}(S)-\frac{124}{27.3 S+1} \operatorname{Mo}(S)+\frac{7.4}{27.3 S+1} P_{1}(S)$

The output pressure is related to the change of speed $\mathrm{M} \mathrm{s}(\mathrm{S})$, the change of signal to anti-surge valve $\mathrm{Mo}(\mathrm{S})$ and the change of suction pressure $\mathrm{P}_{\mathrm{i}}(\mathrm{t})$ Figure 4 .

\section{Mathematical Model of Control Valve and the Transmitter}

The control valve is to be designed for $100 \%$ overcapacity, and pressure drop variations can be neglected. The valve is a linear valve characteristic with a time constant of 3 seconds [1]. The transfer

\begin{tabular}{|c|c|c|}
\hline Parameter & Value & Unit \\
\hline Suction Pressure & 235 & psia \\
\hline Discharge Pressure & 565 & psia \\
\hline Max. Discharge Press. & 600 & psia \\
\hline Suction Temperature & $76+460$ & $\mathrm{R}^{\circ}$ \\
\hline Discharge Temperature & $220+460$ & $\mathrm{R}^{\circ}$ \\
\hline Inlet Flow at 13500 RPM $100 \%$ speed & 2.633 & Mmscf/h \\
\hline Max. flow through Anti surge valve & 3.625 & Mmscf/h \\
\hline Outlet pipe diameter & $D=16 "$ & inch \\
\hline Orifice diameter & $d=9 "$ & inch \\
\hline diameters ratio $\beta$ & 0.6 & \\
\hline Diff. Pres. Across orifice $\Delta \mathrm{P}$ & 25 & Inch $\mathrm{H} 2 \mathrm{O}$ \\
\hline Orifice coefficient $\mathrm{C}$ & 22585 & \\
\hline Gas density & 0.64 & \\
\hline Valve coefficient $\varepsilon$ & 0.99 & \\
\hline Suction gas pressure factor & 0.964 & \\
\hline Signal to Anti Surge valve at SS & 95 & $\%$ \\
\hline Signal to compressor speed & 75 & $\%$ \\
\hline Calc. Valve coefficient Cv & 133.9 & \\
\hline Actual Valve coefficient $\mathrm{Cv}$ & 236 & \\
\hline Gas Molecular wight & 20.3 & \\
\hline
\end{tabular}
function for a linear valve with pressure drop is constant:

Table 1: Data of the Solar Compressor in Sirt Oil Co.

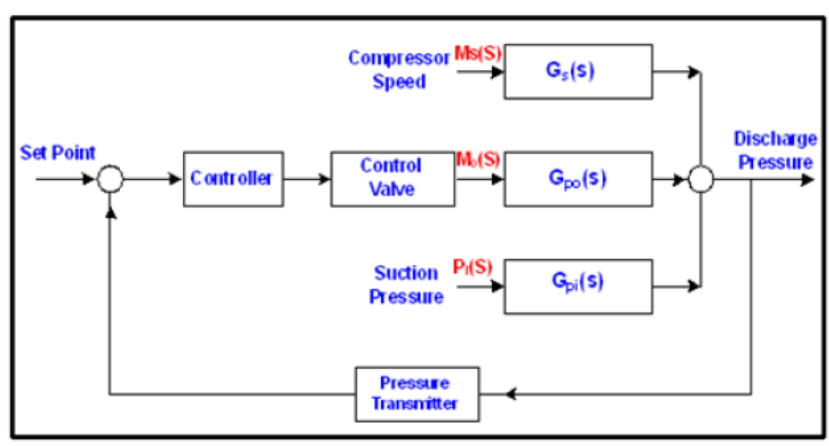

Figure 4: Block diagram of transfer function. 


$$
G_{v}(S)=\frac{K_{v}}{\tau_{v} S+1}
$$

Where $\mathrm{Kv}$ is the valve gain, it can be calculated by the flow through the valve in $\%$ to the controller output signal in percent and ( $\tau v)$ is the valve time constant.

Substitute in (15) yelled:

$$
G_{v}(S)=\frac{1}{3 S+1}
$$

The transmitter transfer function can be considered as gain only; it is equal to percentage of transmitter output to its input $=100 \% / 100 \%$ $=1$

$$
\mathrm{G}_{\mathrm{T}}(s)=1
$$

\section{General Tips for Designing a PID Controller}

The main idea of root locus design is to estimate the closed-loop response from the open-loop root locus plot. By adding zeros and/or poles to the original system (adding a compensator), the root locus and thus the closed-loop response will be modified. Figure 5 the closed loop of the system. The open loop transfer functions of the process and valve:

$$
G(S)=\frac{124}{81.9 S^{2}+31.9 S+1}
$$

Let's first view the response of the closed loop with proportional controller only and $\mathrm{Kp}=1$, and no load effects of speed and suction pressure is considers (Figure 6). Then the root locus for the open loop is viewed. In the $\mathrm{m}$-file we add the following command and then run the file to get the root locus plot below Figure 7 . We have two poles on the real axis and no zeros. The two zeros are in the infinity. The response of closed loop shows that the overshoot is about $60 \%$ and the settling time is so large. In order to pull the root locus further to the left, to make it faster, we need to place a second open-loop zero, resulting in a PID controller Figure 8.

\section{Finding coefficient $\mathrm{K}$ :}

$>>[\mathrm{k}$, poles $]=\operatorname{rlocfind}($ numf,denf $)$

Select a point in the graphics window

Selected point $=-0.2479+0.0242 \mathrm{i}$

$\mathrm{k}=1.1649$

Poles $=-1.6402$

$-0.2529+0.0238 \mathrm{i}$

$-0.2529-0.0238 \mathrm{i}$

We made some experiments for receiving a good response Figure 9.

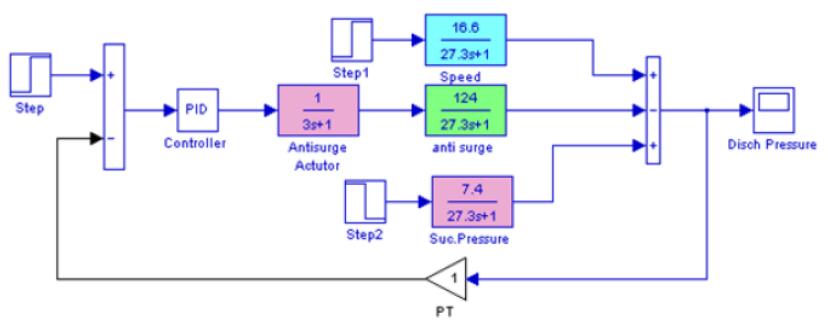

Figure 5: Block diagram of the closed loop system.
So, from this experiment we learnt that if we use a PID controller with:

$\mathrm{K}_{\mathrm{p}}=17, \mathrm{~K}_{i}=2$ and $\mathrm{K}_{d}=3$ values we meet the required response.

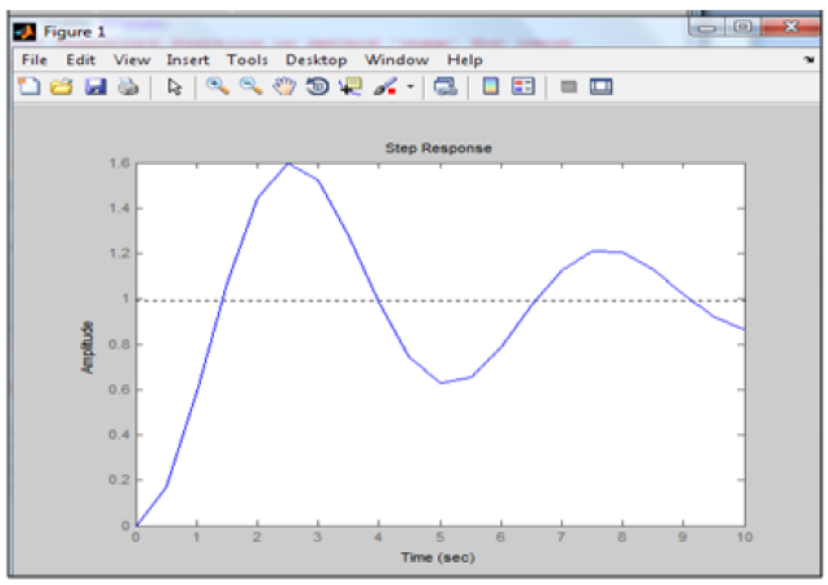

Figure 6: Response of the open loop with proportional controller.

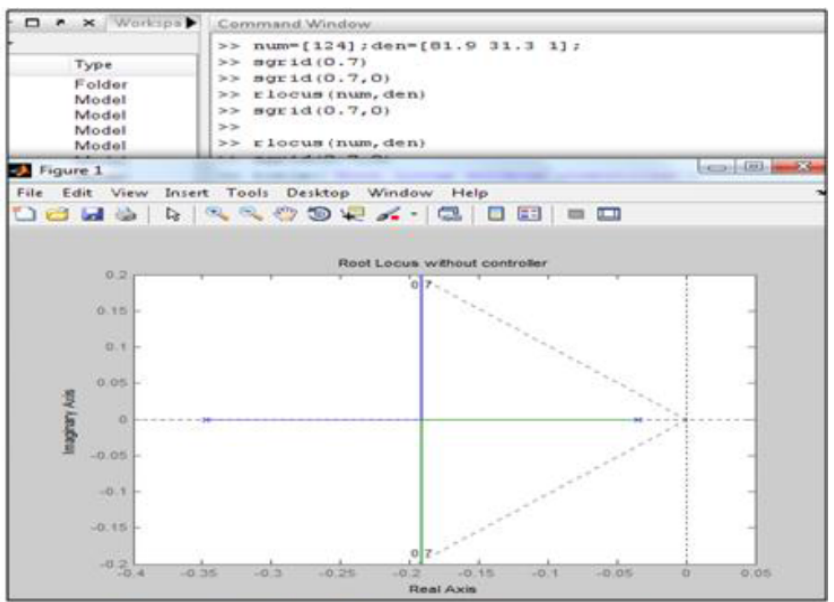

Figure 7: Root locus without controller.

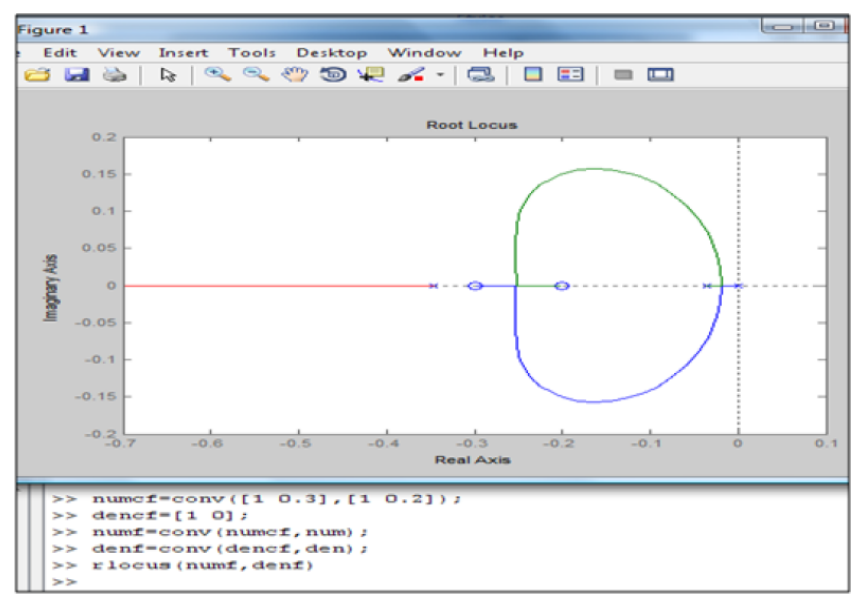

Figure 8: Root locus with PID controller. 


\section{Evaluating Control System}

The control system is a single loop system with two disturbances; the change of suction pressure and the change of speed as shown in Figure 10. The main control aim is to keep the discharge pressure is constant, but in the event of any change of suction pressure or speed will effect on the suction flow and to the discharge pressure.

When the simulation was started and a step input $(5$ psi on discharge pressure set point $=5$ psi and 50 RPM increasing disturbance input on speed with decreasing the suction pressure by 2 psi) was applied a response as shown in the Figure 11 were produced It can be seen that the response was quick enough and the anti- surge system work satisfactory.

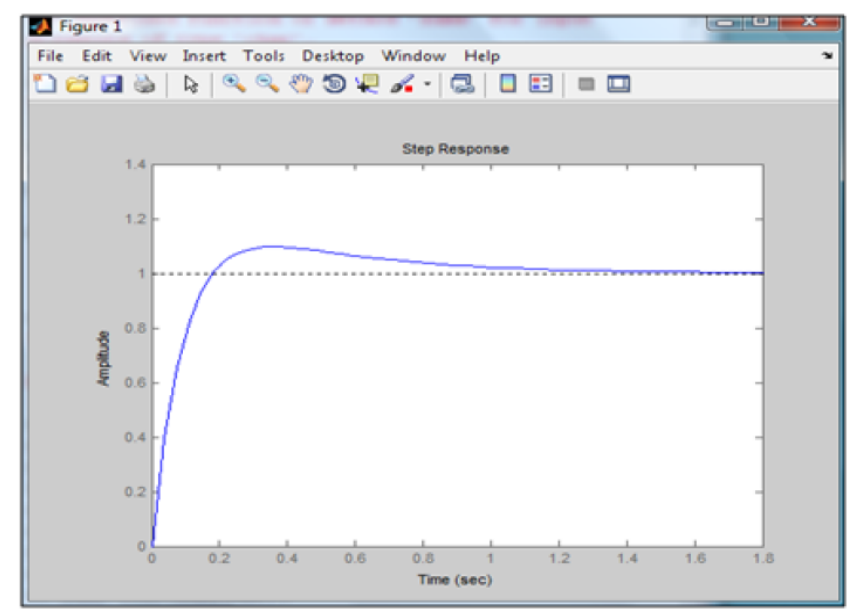

Figure 9: Response of the loop with PID controller.

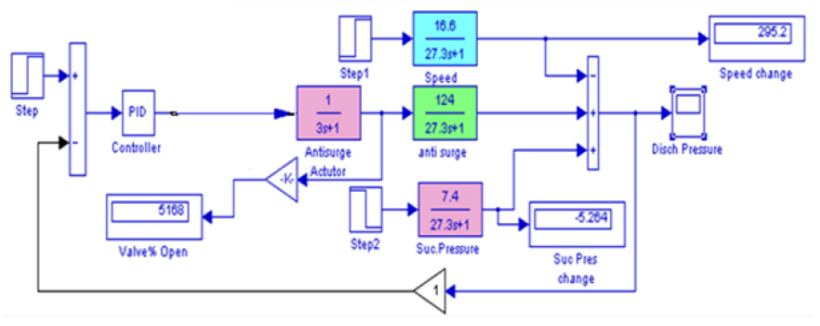

Figure 10: Simulink block diagram of transfer function.

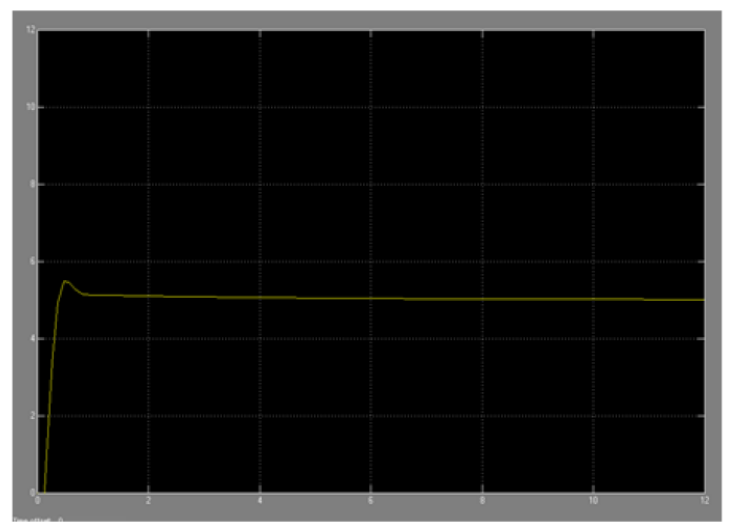

Figure 11: Response of centrifugal control system.

\section{Conclusions and Recommendations}

\section{Conclusions}

1. Development of a dynamic compressor model to evaluate transient behavior of centrifugal compressors during disturbance change.

2. Development of a simple simulation model of a centrifugal compressor with surge avoidance control, based on experimental data.

3. Using MATLAB-SIMULINK we gave a qualitative evaluation of the behaviour of the modeled centrifugal compressor and surge avoidance controller for various disturbances.

\section{Recommendations for further research are}

Investigate the effect of varying molecular weight of the compressor working gas to the anti- surge control systems.

\section{References}

1. Helvoirt JV (2007) Centrifugal Compressor Surge Modeling and Identification for Control.

2. Horowitz FB, Gupta BP, Lipták BG. Compressor Control and Optimization, Volume 2.

3. Willems FPT (2000) Modelling and bounded feedback stabilization of centrifuga compressor surge. Int J Logist Manag.

4. Nuovo Pignone attahady Gas Plant Documentation.

5. Gresh TM (2001) Compressor Performance: Aerodynamics for the User, 2nd Edition, Publisher: Elsevier Science \& Technology Books.

6. Dekker M (2003) Centrifugal Compressors and Fans, Copyright, Inc.

7. Brun K, Nored MG (2008) Application Guideline for Centrifugal compressor Surge Control Systems. GMRC Resource Library.

8. Pampreen RC (1993) Compressor surge and stall. Concepts ETI Inc.

9. Henrie M, Carpenter RP, Nicholas E (2009) Pipeline Rules of Thumb Hand Book. Gulf Professional Publishing.

10. Solar Turbines for SIRTE Oil Company Documentation. 